$06.1 ; 06.5$

\title{
Использование импульсного лазерного отжига для формирования омических контактов Мо/Ті к алмазу
}

\author{
() М.Н. Дроздов ${ }^{1}$, Е.А. Архипова ${ }^{1}$, Ю.Н. Дроздов ${ }^{1}$, С.А. Краев ${ }^{1}$, В.И. Шашкин ${ }^{1}$, А.Е. Парафрин ${ }^{1}$, \\ М.А. Лобаев ${ }^{2}$, А.Л. Вихарев ${ }^{2}$, А.М. Горбачев ${ }^{2}$, Д.Б. Радищев ${ }^{2}$, В.А. Исаев ${ }^{2}$, С.А. Богданов ${ }^{2}$ \\ ${ }^{1}$ Институт фризики микроструктур РАН, Нижний Новгород, Россия \\ ${ }^{2}$ Институт прикладной физзики РАН, Нижний Новгород, Россия \\ E-mail: drm@ipm.sci-nnov.ru
}

Поступило в Редакцию 25 февраля 2020г.

В окончательной редакции 10 марта 2020 г.

Принято к публикации 12 марта 2020г.

Исследуется влияние импульсного лазерного отжига на процесс формирования омических контактов Мо/Ті к алмазу. С использованием метода вторично-ионной масс-спектрометрии показано, что лазерный отжиг контактов приводит к эффективной диффузии атомов углерода в слой титана и формированию карбида титана в переходной области с алмазом толщиной $15-20 \mathrm{~nm}$. Быстрый термический отжиг такой же контактной системы сопровождается резким возрастанием содержания кислорода в слое титана и переходном слое с алмазом и возникновением окисла титана. При этом фаза карбида титана в переходном слое $\mathrm{Ti}-\mathrm{C}$ не формируется. Показано также, что в использованном режиме лазерного отжига не происходит графитизации приконтактного слоя алмаза, что могло бы кардинально снизить механическую прочность и адгезию контактов.

Ключевые слова: алмаз, омические контакты, отжиг, карбиды, окислы, графитизация.

DOI: 10.21883/PJTF.2020.11.49497.18261

При изготовлении омических контактов к алмазу важную роль играет формирование промежуточного проводящего слоя карбида металла на границе с алмазом, что позволяет решить проблемы низкого коэффициента диффузии атомов металлов в алмазе и отсутствия сплавов эвтектики металлов с углеродом с низкой температурой плавления. Переходный слой карбидов повышает адгезию контактов к алмазу, улучшает механические свойства и увеличивает теплопроводность контактов $[1,2]$. Кроме того, наличие карбида уменьшает потенциальный барьер перехода металл-алмаз и снижает контактное сопротивление $[3,4]$, что особенно актуально в связи с большой шириной запрещенной зоны алмаза и невозможностью применить инженерию работы выхода металлов для создания омических контактов с низкой высотой барьера. Поэтому для изготовления омических контактов используются металлы с наибольшими значениями отрицательной свободной энергии образования карбида: Ti, Мо, Тa, W. Для формирования карбидов важную роль играют условия процесса высокотемпературного отжига, в первую очередь отсутствие кислорода на границе металла с алмазом. При наличии кислорода происходит образование окислов, а не карбидов металлов. Наиболее распространенный способ отжига контактов - быстрый термический отжиг в потоке инертных газов высокой чистоты - не обеспечивает достаточной защиты от проникновения кислорода к границе с алмазом через слои металлов. Для такого отжига необходимо формировать дополнительные защитные слои, препятствующие диффузии кислорода через внешнюю поверхность, например $\mathrm{Au} / \mathrm{Pd} / \mathrm{Ti}$ или $\mathrm{Au} / \mathrm{Mo} / \mathrm{Ti}$. Роль отдельных защитных слоев металла - Au и Мо - изучалась в [5]. В работах [6-8] исследовалось формирование карбида титана на границе титан-алмаз (или аморфный углерод) при отжиге в высоковакуумной установке при давлении $10^{-6}-10^{-7}$ Torr $[6,7]$ либо в атмосфере высокочистого гелия [8]. Однако даже в условиях высокого вакуума для формирования карбида титана при отжиге оказалось необходимым осаждать дополнительные барьерные слои на поверхности слоя титана, чтобы избежать доминирующего процесса окисления титана из остаточной атмосферы вакуумной камеры. Насколько известно авторам настоящей работы, в установках сверхвысокого вакуума при давлении $10^{-9}-10^{-10}$ Torr подобные исследования отжига не проводились. Альтернативой быстрому термическому отжигу может служить импульсный лазерный отжиг. Это очень быстрый процесс, при котором кислород не успевает диффундировать в контактную систему даже при отжиге в нормальных атмосферных условиях. В работе [9] лазерный отжиг использовался для формирования омических контактов с пониженным контактным сопротивлением к другому широкозонному материалу - GaN. Для алмазов лазерный отжиг использовался в технологиях лазерной резки и гравировки, а также с целью непосредственного создания графитовых контактов в результате графитизации алмаза [10]. Насколько известно авторам работы, для изготовления омических контактов к алмазу на основе слоев металла лазерный отжиг как альтернатива быстрому термическому отжигу не использовался. Повидимому, это связано с опасением протекания побочного явления графитизации слоя алмаза под действием 
лазерного излучения, что приведет к деградации механических свойств контактов. В настоящей работе с использованием метода вторично-ионной масс-спектрометрии (ВИМС) исследуется модификация атомного состава контактной системы Мо/Ті к алмазу. Основное внимание уделено изменению концентрации примеси кислорода, свойствам переходной области Ті-алмаз и выявлению фазы графита в приконтактном слое алмаза. Проводится сравнение с результатами быстрого термического отжига такой системы.

Эпитаксиальные слои алмаза толщиной $300 \mathrm{~nm}$ выращивались на монокристаллических подложках алмаза фирмы „Нью Даймонд Технолоджи“ [11]. Рост пленок проводился в CVD-реакторе. Плазма CBЧ-разряда поддерживалась в смеси $\mathrm{H}_{2}-\mathrm{CH}_{4}$ излучением магнетрона на частоте $2.45 \mathrm{GHz}$ [12]. Металлические слои $\operatorname{Mo}(d=30 \mathrm{~nm}) / \operatorname{Ti}(d=20 \mathrm{~nm})$ осаждались на алмаз методом электронно-лучевого испарения на установке Amod 206 с криогенной откачкой. Для лазерного отжига использовался импульсный лазер LPX-200 ( $\mathrm{KrF})$, длина волны $\lambda=248 \mathrm{~nm}$, длительность импульса $\tau=30 \mathrm{~ns}$, плотность энергии $1 \mathrm{~J} / \mathrm{cm}^{2}$, число импульсов варьировалось от 1 до 7. Коэффициент поглощения алмаза на этой длине волны составляет менее $10^{-1} \mathrm{~cm}^{-1}[13]$, поэтому незакрытая контактом область алмаза при лазерном воздействии практически не нагревается. Отметим, что для лазерной резки и гравировки алмаза, а также для формирования графитовых контактов используется лазерное излучение с длиной волны меньше $200 \mathrm{~nm}$, для которой коэффициент поглощения алмаза резко возрастает и составляет более чем $10^{3} \mathrm{~cm}^{-1}$. Термический отжиг контактов проводился на установке быстрого термического отжига в потоке высокочистого аргона $\operatorname{Ar}$ (99.999\%). Анализ атомного состава осуществлялся методом времяпролетной вторично-ионной масс-спектрометрии на установке TOF.SIMS-5. Распыление поверхности проводилось ионами цезия с энергией $1 \mathrm{keV}$, зондирование ионами висмута $\mathrm{Bi}_{3}^{+}$с энергией $25 \mathrm{keV}$. Для определения содержания $s p^{3}$ - и $s p^{2}$-гибридных состояний атомов углерода использовалась методика фазового анализа, развитая в работе [14] на основе регистрации кластерных вторичных ионов $\mathrm{C}_{7}$ и $\mathrm{C}_{8}$. Глубина кратеров распыления измерялась на установке оптической профилометрии Talysurf CCI-2000.

На рис. 1, $a-c$ приведены профили концентрации атомов углерода, титана и молибдена в исходной контактной системе и после процессов лазерного и термического отжига. Эти профили получены при регистрации положительных вторичных ионов C, CsTi и CsMo. Интенсивность вторичных ионов для каждого элемента нормировалась на сумму интенсивностей всех элементов. Такой режим измерений позволяет в значительной степени избежать матричных эффектов ВИМС. Рис. $1, a$ и $b$ показывают, что после лазерного отжига ширина перехода Тi/C увеличилась с 5 до $15 \mathrm{~nm}$. После термического отжига при $850^{\circ} \mathrm{C}$ ширина перехода $\mathrm{Ti} / \mathrm{C}$ практически не изменилась и составляет $6 \mathrm{~nm}$ (рис. 1, $c$ ).
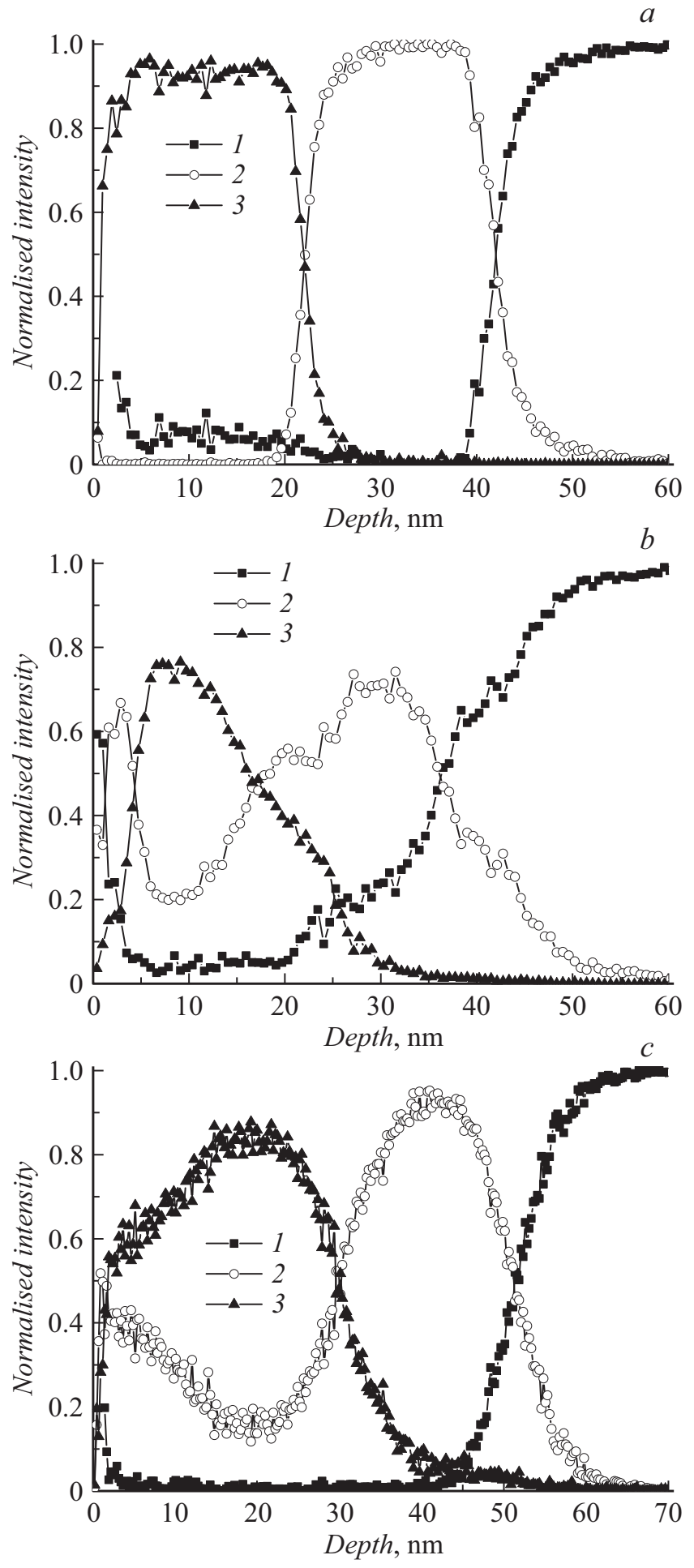

Рис. 1. Профили концентрации атомов углерода, титана и молибдена в исходной контактной системе $(a)$, после лазерного отжига $(b)$ и после быстрого термического отжига $(c) .1-\mathrm{C}$, $2-\mathrm{Ti}, 3-\mathrm{Mo}$.

Эти результаты свидетельствуют об эффективной диффузии атомов углерода в слой титана при лазерном отжиге. При термическом отжиге взаимодиффузия атомов углерода и титана практически отсутствует. Рис. 1, $c$ 

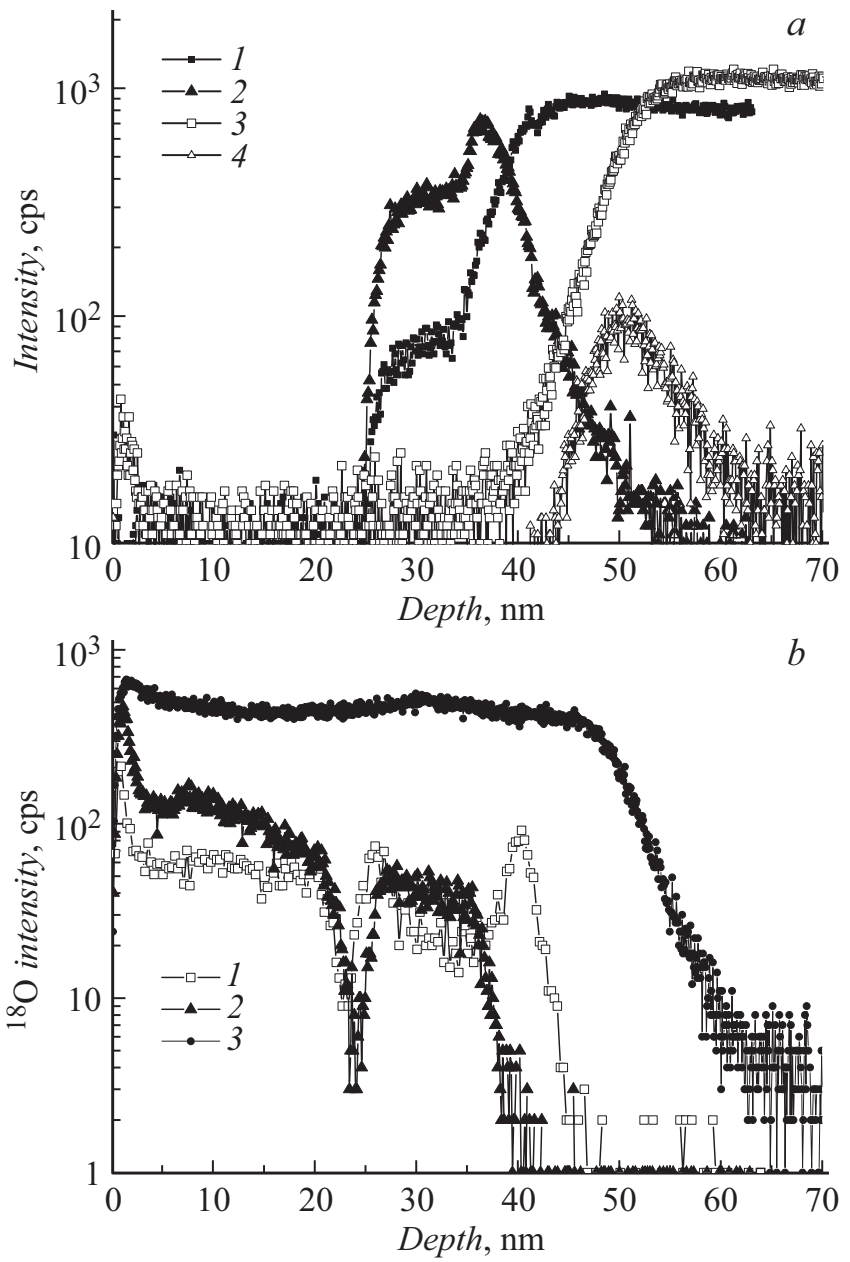

Pис. 2. $a-$ профили интенсивности отрицательных вторичных ионов ${ }^{13} \mathrm{C}(1,3)$ и $\mathrm{TiC}(2,4)$ после лазерного $(1,2)$ и быстрого термического $(3,4)$ отжига. $b-$ профили интенсивности изотопа кислорода ${ }^{18} \mathrm{O}$ в контактной системе после осаждения слоев Ті и Мо (1), после лазерного (2) и термического (3) отжига.

также показывает, что после быстрого термического отжига полная толщина контактного слоя возросла на $\sim 7 \mathrm{~nm}$. Рост толщины контактных слоев после отжига наблюдался и ранее [5], он связывается с ,разбуханием“ слоя Ті из-за насыщения кислородом.

На рис. 2, а приведены профили интенсивности отрицательных вторичных ионов ${ }^{13} \mathrm{C}$ и ТіС после лазерного и термического отжига. Наиболее показательным является различие профилей кластерных вторичных ионов ТiC. При лазерном отжиге профиль ионов ТіС имеет хорошо выраженный плоский участок с высокой интенсивностью в переходной области $\mathrm{C}-\mathrm{Ti}$. В этой же области профиль интенсивности ионов углерода ${ }^{13} \mathrm{C}$ имеет два участка с различной характерной длиной спада на порядок $L_{d e c}$ : на глубине $35-40 \mathrm{~nm} L_{d e c}=5-7 \mathrm{~nm}$, в области $25-35 \mathrm{~nm}$ $L_{d e c} \sim 25-30 \mathrm{~nm}$. При термическом отжиге ионы ТiC возникают только на границе перехода $\mathrm{C}-\mathrm{Ti}$. Такая комбинация вторичных ионов элементов из двух соседних слоев возникает всегда в пределах глубины разрешения ВИМС. Профиль ионов ${ }^{13} \mathrm{C}$ после термического отжига имеет монотонный спад с характерным масштабом $L_{d e c}=5-7 \mathrm{~nm}$. На наш взгляд, большая длина диффузии атомов углерода в слой титана $\sim 15-20 \mathrm{~nm}$ и наличие кластерных вторичных ионов из элементов Ті и С с высокой интенсивностью свидетельствуют о протекании при лазерном отжиге процесса реакционной диффузии атомов углерода, включающей формирование соединения карбида титана. При термическом отжиге таких эффектов не наблюдается, и взаимодиффузия атомов углерода и титана незначительна.

На рис. 2, $b$ приведены профили интенсивности изотопа кислорода ${ }^{18} \mathrm{O}$ в контактной системе после осаждения слоев Ті и Мо (кривая 1) и после лазерного и термического отжига (кривые 2 и 3). В исходной контактной системе концентрация примеси кислорода в слоях Ті и Мо не превышает нескольких процентов. После лазерного отжига концентрация кислорода слабо возрастает в слоях Мо и Тi, при этом на границе Тi-C концентрация кислорода снижается в результате его ухода в слой Ti. Существенное повышение содержания кислорода после лазерного отжига на рис. $2, b$ наблюдается только в поверхностном слое молибдена толщиной $3 \mathrm{~nm}$. После термического отжига концентрация кислорода возрастает больше чем в 10 раз в обоих слоях (Мо и Ті) и составляет несколько десятков процентов. Возрастание концентрации кислорода приводит к образованию окисла титана, что блокирует формирование карбида титана. Это объясняет разницу профилей $\mathrm{TiC}$ и ${ }^{13} \mathrm{C}$ после лазерного и термического отжига на рис. 2, $a$. Отметим, что на рис. $2, a$ и $b$ используются изотопы углерода ${ }^{13} \mathrm{C}$ и кислорода ${ }^{18} \mathrm{O}$, поскольку основные изотопы ${ }^{12} \mathrm{C}$ и ${ }^{16} \mathrm{O}$ имеют высокую интенсивность и при их регистрации детектор вторичных ионов насыщается в отдельных слоях.

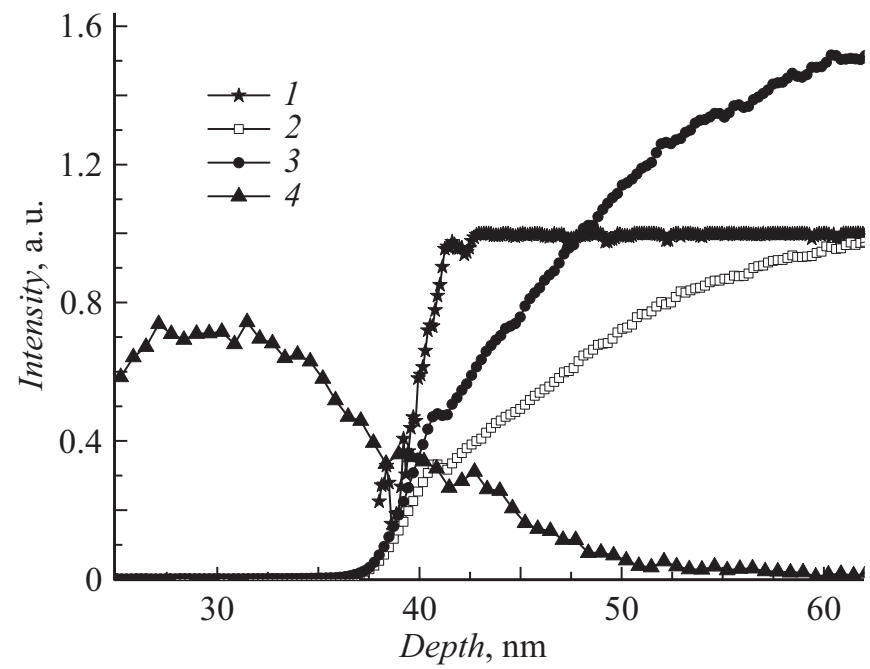

Рис. 3. Профили $N\left(s p^{3}\right)(1)$, интенсивности кластерных вторичных ионов $\mathrm{C}_{7}(2), \mathrm{C}_{8}(3)$ и Ті (см. рис. $\left.1, b\right)(4)$ после лазерного отжига. 
Информация о возможной графитизации алмаза в приконтактной области была получена на основе анализа содержания атомов углерода в состоянии $s p^{3}$-гибридизации $N\left(s p^{3}\right)$ согласно методике работы [14]. Профиль $N\left(s p^{3}\right)$ в приконтактной области алмаза после лазерного отжига приведен на рис. 3 (кривая 1). Там же приведены профили интенсивности кластерных вторичных ионов $\mathrm{C}_{7}$ и $\mathrm{C}_{8}$, нормированные на максимальное значение интенсивности $\mathrm{C}_{7}$ (кривые 2 и 3), и концентрации титана (см. рис. $1, b)$ (кривая 4). Профиль $N\left(s p^{3}\right)$ вычислялся по полиному второй степени от отношения $\mathrm{C}_{8} / \mathrm{C}_{7}$, коэффициенты в котором определены в работе [14] с использованием тестовых структур. В слое алмаза на глубине больше $55 \mathrm{~nm}$ (вдали от перехода) величина $N\left(s p^{3}\right)=1$. Начиная от слоя алмаза величина $N\left(s p^{3}\right)$ сохраняет это же значение вплоть до глубины $42 \mathrm{~nm}$, где уже происходит снижение концентрации углерода и возрастание концентрации титана в переходной области Тi-C. При этом интенсивности вторичных ионов $\mathrm{C}_{7}$ и $\mathrm{C}_{8}$ снижаются в 4 раза, однако их отношение остается неизменным. На глубине меньше $38 \mathrm{~nm}$ профиль $N\left(s p^{3}\right)$ не приводится, поскольку из-за сильного падения концентрации углерода резко возрастает уровень шумов отношения $\mathrm{C}_{8} / \mathrm{C}_{7}$. Кроме того, в этой области калибровка работы [14] теряет справедливость, поскольку она применима только для углеродсодержащих материалов с низким содержанием примесей. Такое поведение отличается от поведения профиля $N\left(s p^{3}\right)$ в слое алмаза после лазерной резки, полученного в работе [15]. В этой работе величина $N\left(s p^{3}\right)$ варьировалась от 0.1 до 1 в приповерхностном слое алмаза толщиной более $100 \mathrm{~nm}$ при постоянной концентрации атомов углерода, что показало высокую концентрацию фазы графита в данном слое. Профиль $N\left(s p^{3}\right)$ на рис. 3 показывает, что в использованном режиме лазерного отжига графитизации алмаза в приконтактной области не происходит.

Таким образом, в работе показано, что импульсный лазерный отжиг омических контактов Мо/Ті к алмазу приводит к эффективной диффузии атомов углерода в слой титана и формированию карбида титана в переходной области и не сопровождается заметным возрастанием примеси кислорода. Быстрый термический отжиг такой контактной системы в атмосфере высокочистого аргона сопровождается резким возрастанием примеси кислорода в слое титана и переходном слое с алмазом и возникновением окисла титана. При этом фаза карбида титана в переходном слое $\mathrm{Ti}-\mathrm{C}$ не формируется. Такой контакт без промежуточного слоя карбида имеет плохую адгезию к алмазу и оказывается механически непрочным. Показано также, что в использованном режиме лазерного отжига не происходит графитизации приконтактного слоя алмаза, что могло бы кардинально снизить механическую прочность и адгезию контактов. Поэтому импульсный лазерный отжиг может быть использован для решения задачи формирования омических контактов к алмазу с использованием простых систем металли- зации, где быстрый термический отжиг дает неудовлетворительные результаты. Электрические свойства таких контактов будут изучены в отдельной работе. Отметим, что недостатком существующих импульсных лазеров является небольшая площадь однородной засветки с высокой интенсивностью, не превышающая нескольких квадратных сантиметров. Для стандартных полупроводников $\mathrm{Si}, \mathrm{GaAs}, \mathrm{GaN}$ такая площадь недостаточна для технологических операций. Однако для современных работ в области алмазной электроники используются монокристаллические подложки малого размера, для которых существующие системы импульсных лазеров обеспечивают однородную засветку.

\section{Благодарности}

В работе использовалось оборудование ЦКП ИФМ РАН „Физика и технология микро- и наноструктур“.

\section{Финансирование работы}

Работа поддержана Российским фондом фундаментальных исследований (проект № 18-02-00565) в части развития методики ВИМС-анализа углеродсодержащих материалов и Российским научным фондом (№ 17-19-01580) в части изготовления легированных эпитаксиальных пленок алмаза и отработки технологических методов формирования омических контактов для задач алмазной электроники.

\section{Конфликт интересов}

Авторы заявляют, что у них нет конфликта интересов.

\section{Список литературы}

[1] Power electronics device applications of diamond semiconductors / Eds S. Koizumi, H. Umezawa, J. Pernot, M. Suzuki. Woodhead Publishing Ser. in Electronic and Optical Materials. Elsevier, 2018. 452 p.

[2] Духновский М.П., Ратникова А.К., Федоров Ю.Ю. Металлизированная пластина алмаза для изделий электронной техники. Патент РФ. RU 2436189 C1. Опубликовано: 10.12.2011. Бюл. № 34.

[3] Viljoen P.E., Lambers E.S., Holloway P.H. // J. Vac. Sci. Technol. B. 1994. V. 12. N 5. P. 2997-3005.

[4] Kono S., Teraji T., Kodama H., Ichikawa K., Ohnishi S., Sawabe A. // Diamond Relat. Mater. 2015. V. 60. P. 117-122.

[5] Дроздов М.Н., Демидов Е.В., Дроздов Ю.Н., Краев С.А., Шашкин В.И., Архипова Е.А., Лобаев М.А., Вихарев А.Л., Горбачев А.М., Радищев Д.Б., Исаев В.А., Богданов С.А. // ЖТФ. 2019. Т. 89. В. 12. С. 1923-1932.

[6] Venkatesan V., Malta D.M., Das K., Belu A.M. // J. Appl. Phys. 1993. V. 74. N 2. P. 1179-1187.

[7] Yokoba M., Koide Y., Otsuki A., Ako F., Oku T., Murakami M. // J. Appl. Phys. 1997. V. 81. N 10. P. 68156821. 
[8] Leroy W.P., Detavernier C., Van Meirhaeghe R.L., Kellock A.J., Lavoie C. // J. Appl. Phys. 2006. V. 99. N 6. P. 063704 (1-5).

[9] Tzou A.J, Hsieh D.H., Chen S.H., Li Z.Y., Chang C.Y., Kuo H.C. // Semicond. Sci. Technol. 2016. V. 31. N 5. P. 055003.

[10] De Feudis M., Caricato A.P., Chiodini G., Martino M., Alemanno E., Maruccio G., Monteduro A.G., Ossi P.M., Perrino R., Spagnolo S. // Diamond Relat. Mater. 2016. V. 65. P. $137-143$.

[11] Юнин П.А., Волков П.В., Дроздов Ю.Н., Колядин А.В., Королев С.А., Радищев Д.Б., Суровегина Е.А., Шашкин В.И. // ФТП. 2018. Т. 52. В. 11. С. 1321-1325.

[12] Vikharev L.A., Gorbachev A.M., Lobaev M.A., Muchnikov A.B., Radishev D.B., Isaev V.A., Chernov V.V., Bogdanov S.A., Drozdov M.N., Butler J.E. // Phys. Status Solidi RRL. 2016. V. 10. N 4. P. 324-327.

[13] Хмельницкий Р.А., Талипов Н.Х., Чучева Г.В. Синтетический алмаз для электроники и оптики. М.: Изд-во ИКАР, 2017. $228 \mathrm{c}$.

[14] Дроздов М.Н., Дроздов Ю.Н., Охапкин А.И., Юнин П.А., Стрелецкий О.А., Иешкин А.Е. // Письма в ЖТФ. 2020. T. 46. B. 6. C. $38-42$.

[15] Дроздов М.Н., Дроздов Ю.Н., Охапкин А.И., Краев С.А., Лобаев М.А. // Письма в ЖТФ. 2019. Т. 45. В. 2. С. 50-54. 